\title{
VISUALIZAÇÃO DE AMBIENTES INTERNOS ATRAVÉS DE INTERATIVIDADE COMPUTACIONAL PROVIDA POR IMAGENS PANORÂMICAS
}

\section{VIEWING OF INTERNAL ENVIRONMENTS THROUGH INTERACTIVE COMPUTER PROVIDED BY PANORAMIC IMAGES}

\author{
Mateus Messias Cavichioli Coelho ${ }^{1}$; Francisco Assis da Silva ${ }^{1}$; Mário Augusto Pazoti ${ }^{1}$; \\ Danillo Roberto Pereira ${ }^{1}$; Ricardo Luiz Barbosa ${ }^{2}$; Rodrigo Bezerra de Araújo Gallis ${ }^{3}$ \\ ${ }^{1}$ Faculdade de Informática - FIPP, Universidade do Oeste Paulista - UNOESTE \\ e-mail: mateusunderline@hotmail.com, \{chico, mario, danilopereira\}@unoeste.br \\ ${ }^{2}$ Universidade Estadual Paulista - Unesp, Campus de Sorocaba \\ e-mail: ricardo@cartovias.com.br \\ ${ }^{3}$ UFU - Universidade Federal de Uberlândia, Campus Monte Carmelo - MG \\ e-mail: rodrigogallis@gmail.com
}

RESUMO - Este trabalho apresenta uma maneira de visualizar e interagir em ambientes internos, utilizando sequências de imagens panorâmicas com posicionamento registrado no ambiente durante o percurso de deslocamento para realizar a captura. A visualização de ambientes internos pode ser utilizada para diversas finalidades, como uso cultural, comercial, entre outros. Foi utilizada uma câmera LadyBug 5, com uma taxa de 15 quadros por segundo para capturar as sequências de imagens. Foi desenvolvida uma ferramenta para realizar a catalogação das imagens capturadas, formando um segmento para cada caminho imageado. Esses segmentos com as imagens são utilizados em uma aplicação Web, também desenvolvida, usando HTML5, CSS3, JavaScript, e WebGL, que permite a visualização e interatividade no ambiente das imagens.

Palavras-chave: Imagens Panorâmicas; Imagens Panorâmicas Equirretangular; Imagens 360; Vídeo Panorâmico 360.

ABSTRACT - This paper presents a way to view and interact in indoor environments, using sequences of panoramic images with positioning registered in the environment during the way used to perform the capture of images. The viewing of indoor environments can be used for various purposes, such as cultural, commercial, among others. A camera LadyBug 5 was used with a rate of 15 frames per second to capture the image sequences. A tool to perform the cataloging of the captured images was developed, forming a segment for each imaged way. We used these segments with

Recebido em: 25/01/2015

Revisado em: 25/09/2015

Aprovado em: 26/11/2015 the images in a Web application that we developed using HTML5, CSS3, JavaScript, and WebGL, which allows viewing and interactivity on the images of environment.

Keywords: Panoramic Images; Equirectangular Panoramic Images; Images 360; Panoramic Video 360.

\section{INTRODUÇÃO}

As imagens panorâmicas, ao contrário das fotografias comuns que procura focar somente um determinado ponto de vista de uma cena, têm como característica capturar todos os detalhes a sua volta. Os avanços tecnológicos tanto de hardware como de software, linguagens de programação e recursos de visão computacional propiciaram criar imagens panorâmicas de grandes resoluções. Existem alguns fotógrafos que unem em uma única imagem, centenas de pontos que são capturados de diversas imagens de alta resolução, para a criação de gigantescos panoramas, podendo até ser de "Giga pixels" (RIBEIRO, 2012).

Segundo Ribeiro (2012) a fotografia panorâmica digital está se tornando bastante popular entre fotógrafos profissionais, tanto 
quanto com os amadores. A função principal dessas imagens é mostrar um conteúdo não alcançado com a utilização de fotografias convencionais, trazendo uma sensação de imersão no ambiente imageado.

A utilização de imagens panorâmicas tem crescido de forma muito elevada nos últimos tempos, grande parte dos smartphones possuem aplicações que permitem usar suas câmeras para capturar uma sequência de imagens e produzir uma imagem panorâmica, por meio da junção dessas imagens (SILVA et al., 2014). Empresas de grande porte também utilizam de técnicas semelhantes para gerar imagens panorâmicas. Conforme Soares (2011), o Google Inc., empresa dos Estados Unidos que possui um produto de utilização pela internet conhecido como Google Street View, lançado em 2007, disponibiliza imagens panorâmicas que são capturadas por nove câmeras, permitindo um ângulo de visão de 360 graus na horizontal por 290 graus na vertical. Após a captura das imagens, com diferentes posições de visão, elas são juntadas para formar a imagem panorâmica.

Utilizando mais do que somente imagens panorâmicas isoladas, pode-se, a partir da criação de um recurso que mapeia um trajeto imageado constituído de uma sequência de imagens panorâmicas 360 , possibilitar que pessoas possam ter acesso a um ambiente interno sem que seja necessário que elas estejam fisicamente no lugar. Desse modo, este recurso permitiria a imersão dos usuários no ambiente de uma forma mais dinâmica e interativa, não apenas somente por imagens fixas para a apresentação e conhecimento do lugar.

Este trabalho contribui com a criação de uma forma alternativa de navegar e visualizar ambientes internos com o uso de uma sequência de imagens panorâmicas, registradas com o seu posicionamento no percurso de deslocamento da captura, e com isso permitir a navegação e interação mais realística. Para capturar as sequências de imagens usadas no trabalho foi utilizada uma câmera LadyBug 5 da empresa Point Grey. A navegação e visualização podem ser utilizadas de diversas formas, como apresentar um ambiente interno para ser utilizado por empresas e instituições com o intuito cultural ou financeiro.

As demais seções deste trabalho estão organizadas da seguinte maneira: na Seção 2 são relatados os trabalhos relacionados com imagens panorâmicas e de vídeos panorâmicos em 360; na
Seção 3 é apresentada a metodologia proposta no desenvolvimento deste trabalho; a Seção 4 apresenta os experimentos realizados e os resultados obtidos com a utilização dos processos descritos neste trabalho; a Seção 5 apresenta as considerações finais e expõe as conclusões com os experimentos realizados neste trabalho.

\section{TRABALHOS RELACIONADOS}

O trabalho de Hu et al. (2009) apresenta um sistema para permitir a seus usuários uma sensação de tele presença visual. Para isso, os autores utilizaram da aquisição de um vídeo panorâmico 360 em tempo real, transmitido através da internet e apresentado na Caverna Digital da USP, um ambiente com cinco telas que envolvem os usuários.

O trabalho realizado por Ribeiro (2012) tem como base a importância da construção e utilização de visitas virtuais em um contexto escolar como forma de divulgação do patrimônio local. $\mathrm{O}$ autor afirma que as imagens em formato panorâmico, por se adequarem ao ângulo de visão natural, proporcionam ao usuário uma interatividade no ambiente.

Singh e Kosecká (2012) demonstraram a utilização de modelos semânticos para o reconhecimento de cenários. Os autores utilizaram imagens panorâmicas capturadas com uma câmera LadyBug, obtendo 12.000 fotos panorâmicas em um percurso de um ambiente urbano. O panorama que eles utilizaram é representado por somente quatro vistas (frente, esquerda, trás e direita) para formar um frame. A vista inferior foi descartada, pois continha partes do carro, e o mesmo aconteceu com a vista do topo, pois não continha muitas informações para o trabalho proposto. Os autores mostram uma forma de reconhecimento de cenário com segmentação baseada em cores, cujo resultado pode ser visto na Figura 1 (a). Entretanto, desta maneira 0 algoritmo de segmentação normalmente gera grandes regiões irregulares com diferentes tamanhos. Para resolver esse problema, os autores utilizaram marcações semânticas, gerando resultados mais satisfatórios. $\mathrm{Na}$ imagem resultante Figura 1 (b) foi marcado o terreno na cor verde, o céu na cor vermelha, as construções em amarelo, os carro em rosa, as árvores em marrom, e na cor preta elementos não rotulados. 


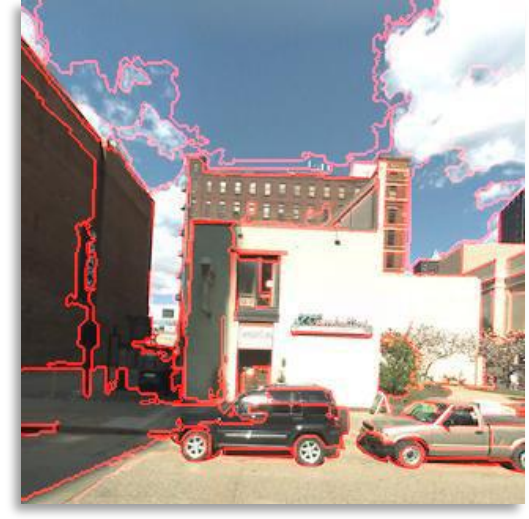

(a)

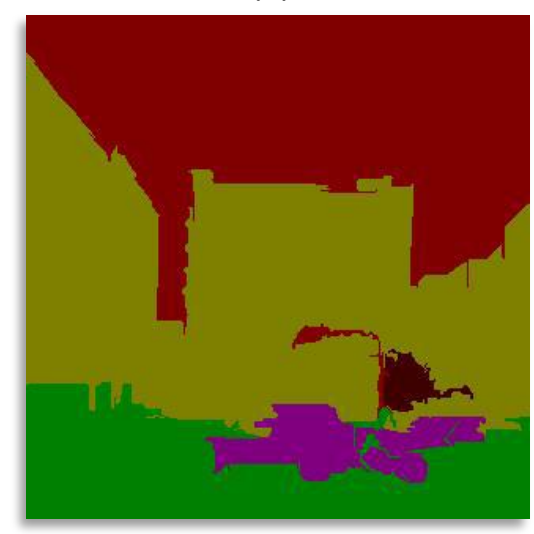

(b)

Figura 1. (a) Segmentação baseada em cores. (b) Segmentação semântica.

Fonte: (SINGH; KOSECKÁ, 2012).

Os autores (SINGH; KOSECKÁ, 2012) conseguiram os resultados apresentados na Figura 1 (b) com análise de layout semântico, considerando tanto a forma geométrica como a aparência apresentada para capturar as estatísticas dos elementos nas regiões. A escolha dos recursos foram escolhidos levando em consideração as informações das regiões dos superpixel, que são áreas da imagem constituída por alguns pixels. Foram consideradas informações como sua localização e forma (posição do centroide, posição relativa, número de pixels e área de imagem), sua cor (valor dos histogramas de cor RGB e HSV, e valores da saturação), textura (média da resposta absoluta de um banco com 15 filtros e histograma das máximas respostas) e com sugestões de perspectivas computadas a partir de segmentos lineares e linhas alinhadas com diferentes pontos de fuga. Os autores usaram um sistema de árvore de decisão para proporcionar a automação na seleção dos recursos para cada uma das classes, e o resultado mais alto dessas classes foi 0 designado para ser o rótulo do superpixel.
A utilização de imagens panorâmicas também foi utilizada no trabalho de Arth et al. (2011), tendo como objetivo permitir melhorar as posições dos atuais sistemas de posicionamento. Aplicações de Realidade Aumentada precisam de melhores precisões nos posicionamentos para a construção de ambientes tridimensionais. Levando em consideração que nem sempre esses posicionamentos estão disponíveis, ou quando estão, possuem grandes margens de erros pelas imprecisões dos sistemas presentes em um smartphone, como por exemplo, os dados do GPS, que depende do aparelho estar em ambiente aberto para funcionar. Estes erros do GPS, de acordo com o autor, está estimado de 10 a 20 metros de imprecisão, outras informações que também nem sempre estão disponíveis, são sistemas de triangulação usados por Bluetoth ou Wi-Fi, que são apenas alternativas razoáveis para ambientes internos. Essas alternativas também possuem muita imprecisão para os níveis requeridos para os sistemas de Realidade Aumentada, argumenta os autores. Arth et al. (2011) propuseram encontrar a relação entre imagens, feita com a correspondência entre pontos de duas imagens, podendo ser usado o algoritmo $\mathrm{SIFT}^{1}$ para auxiliar neste processo. Para a aquisição da imagem panorâmica, os autores levaram em consideração a cooperação do usuário, para que as imagens sejam adquiridas a partir de uma câmera de um celular, sendo obtidas em forma de cilindro ao redor do usuário, considerando que ele não mude de posição durante a criação do panorama, ou seja, apenas considere o movimento de rotação. A partir da aquisição das imagens são procuradas as relações de ligações desta imagem com outras em um banco de dados, a fim de obter pontos semelhantes em relação ao centro do cilindro que foi feita a captura. Isso foi feito para poder calcular a posição do usuário, que é essencial em aplicação de Realidade Aumentada, com necessidade na precisão em produzir e visualizar as informações geradas por estas aplicações.

No trabalho de Álvares (2012), o autor afirma que para um filme tradicional ser visualizado, o utilizador fica limitado ao ângulo de visão em que a câmera do vídeo foi direcionada na captura do vídeo. Com a possibilidade da gravação de um vídeo em 360 graus, não existiria mais esta limitação que o utilizador fica

${ }^{1}$ Algoritmo SIFT: Algoritmo usado para extrair e descrever pontos chaves de uma imagem, com extração de vetores característicos ao redor dos pontos chaves (LOWE, 2004) 
condicionado, permitindo que novas direções sejam exploradas, como com o que acontece na visualização e navegação em hipervídeos imersivos. Álvares (2012) expressa ainda que com o grande desenvolvimento tecnológico e com o acesso a conteúdos audiovisuais em diversas plataformas, tem crescido e facilitado o acesso a dispositivos que possibilitam captura de vídeo em 360 graus e ao registro de posicionamento de referência geográfica (GPS). Diante deste contexto, o autor afirma que seria interessante a criação de novas técnicas que permitam a navegação, visualização e interação com hipervídeos imersivos em 360 graus com sincronização com um mapa. O grande desafio para a apresentação destes tipos de hipervídeos está em proporcionar formas de navegações adequadas para que os utilizadores tenham interfaces capazes de explorar estes conteúdos e facilmente compreender a estrutura destes hipervídeos.

\section{METODOLOGIA PROPOSTA}

Para imagear os ambientes nos experimentos realizados foi utilizada uma câmera LadyBug 5 (Spherical Digital Video Camera - LD551S5C-44), que faz a captura de seis imagens, cada uma com seu ângulo de visão. Para isso são utilizadas seis câmeras posicionadas em diferentes direções, sendo cinco para cobrir a área na horizontal, e uma para captar a visão superior. $\mathrm{O}$ arquivo gerado pela câmera durante a captura de imagens é constituído de uma sequência de 15 capturas por segundo. A Figura 2 mostra a câmera LadyBug 5 utilizada neste trabalho.

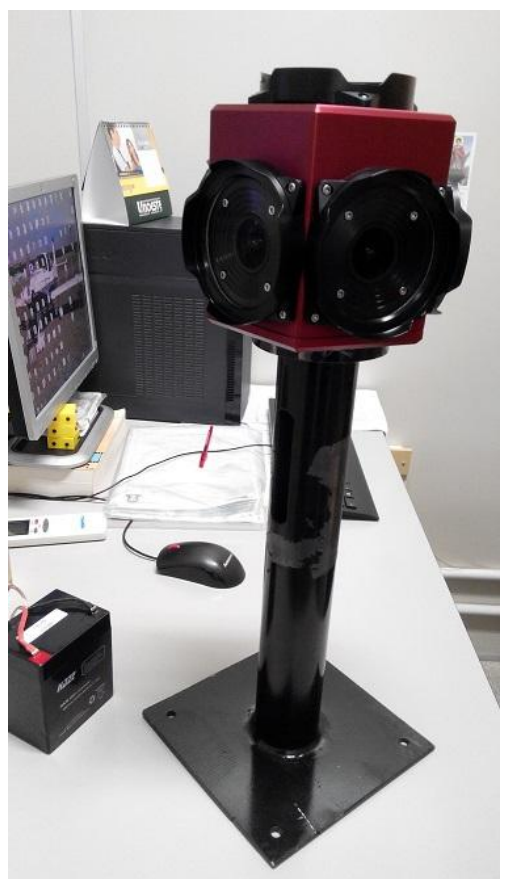

Figura 2. Câmera LadyBug 5 usada na captura das imagens do trabalho.

A câmera foi acoplada a uma haste, para que a captura das imagens não atingissem a cabeça da pessoa que estava transportando-a.

Foi utilizada uma bateria de 12 Volts com 5 Amperes (Figura 3) para fornecer energia para a câmera, o que foi suficiente para propiciar a captura de imagens durante aproximadamente uma hora.

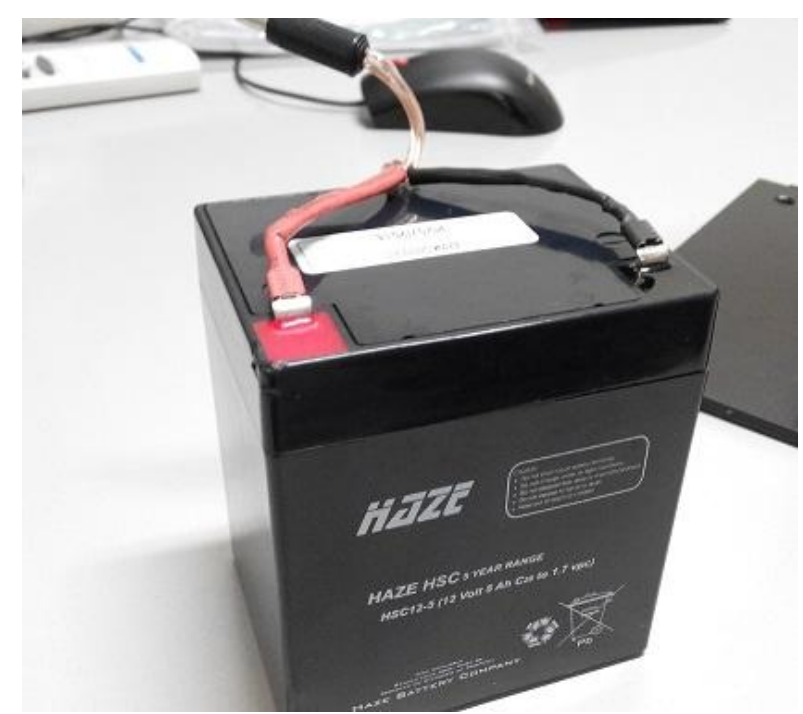

Figura 3. Bateria utilizada para fornecer energia para a câmera LadyBug 5.

A Figura 4 mostra o esquema da ordem com que as etapas são executadas desde a captura das imagens até a visualização e navegação delas na aplicação Web. 


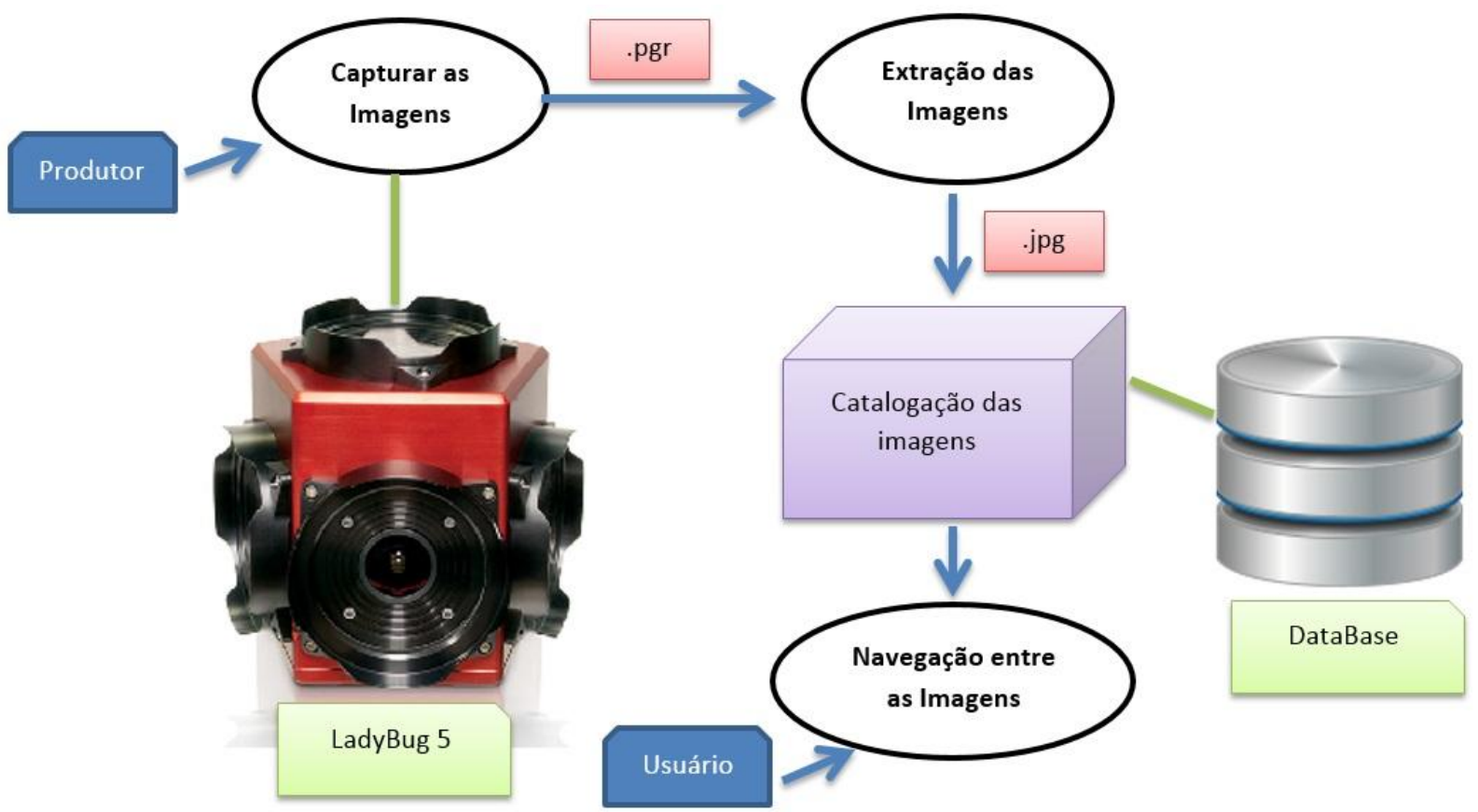

Figura 4. Esquema de captura, extração, catalogação e navegação na aplicação Web.

Após realizar a captura das imagens, faz-se necessário extrair as seis imagens geradas neste arquivo para gerar as imagens panorâmicas. Para isso foi utilizado o kit de desenvolvimento Ladybug SDK 1.14.3.6 para a linguagem de programação C\# fornecido pela empresa criadora da câmera. A Figura 5 mostra a tela da ferramenta construída para realizar a extração das imagens panorâmicas a partir do arquivo gravado durante a captura.

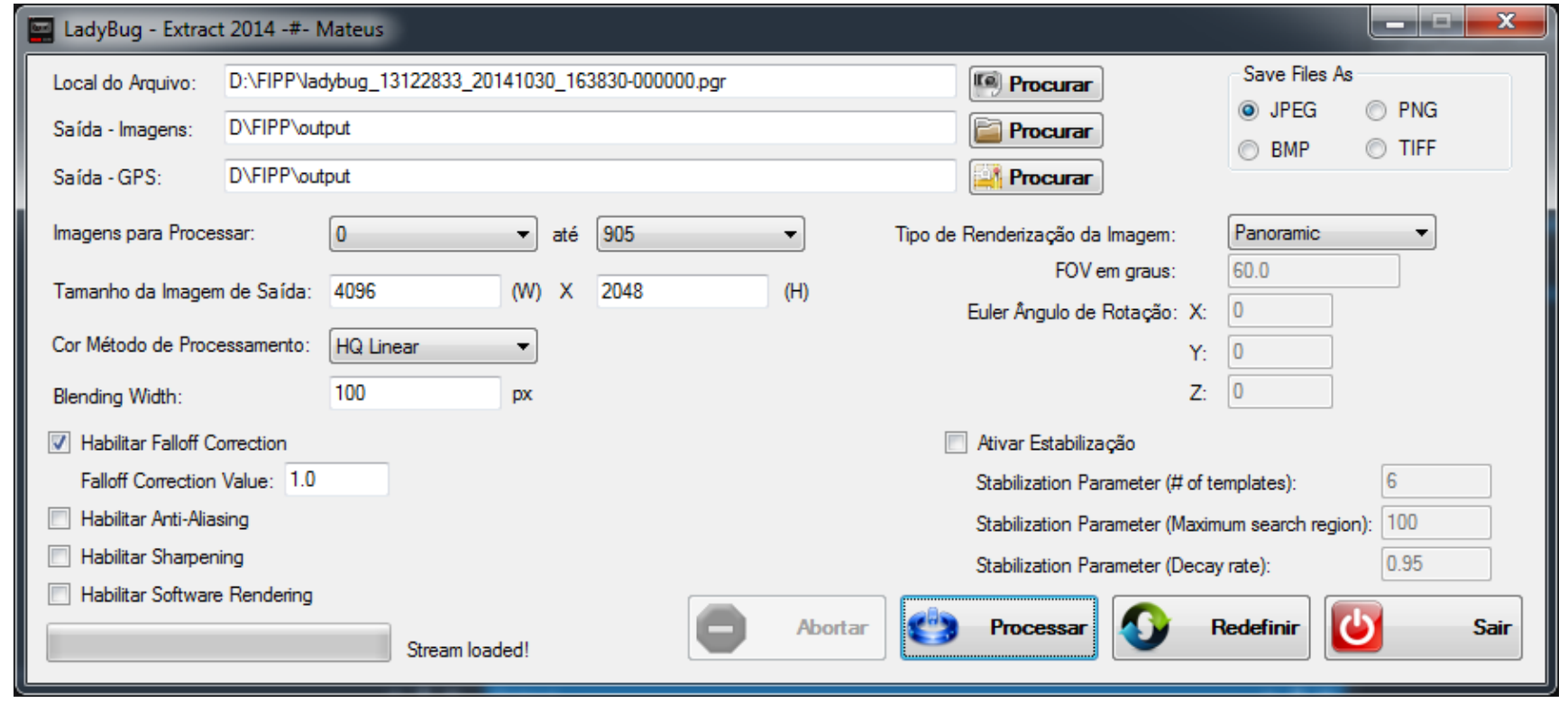

Figura 5. Ferramenta de extração das imagens panorâmicas capturadas pela LadyBug 5.

A Figura 6 (a) mostra seis imagens que constituem um dos frames que as lentes da câmera LadyBug capturaram de uma cena. $\mathrm{Na}$ Figura 6 (b), pode-se visualizar a imagem panorâmica equirretangular ${ }^{2}$ resultante da junção das seis imagens capturadas pela LadyBub. Essa cena foi extraída de um dos frames capturados em um dos corredores do ambiente

\footnotetext{
${ }^{2}$ Imagem panorâmica equirretangular: É uma imagem panorâmica com projeção esférica tendo o campo de visão com 360 graus na horizontal e 180 graus na vertical (MORATO, 2009).
} 
interno do Bloco $\mathrm{H}$ da Unoeste (Universidade do Oeste Paulista) Campus I.

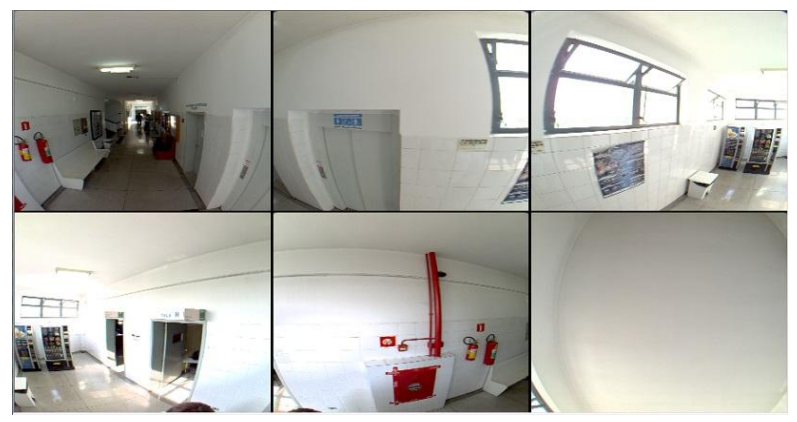

(a)

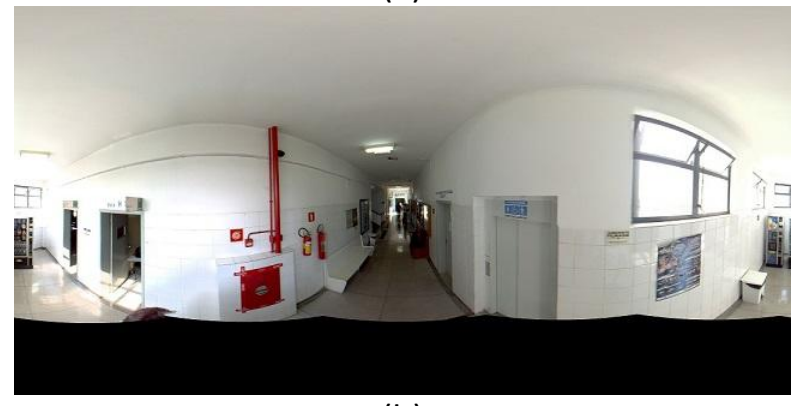

(b)

Figura 6. (a) Seis imagens que constituem um frame de captura da LadyBug. (b) Imagem panorâmica equirretangular resultante da junção das seis imagens do frame capturado.

A partir da geração das imagens panorâmicas, o próximo passo é a catalogação dessas imagens nos caminhos que foram percorridos durante a captura. Para que isso possa ser realizado, foi construída uma ferramenta para realizar essa catalogação das imagens, formando um segmento para cada caminho imageado (Figura 8). As imagens são catalogadas, e a cada imagem é adicionado um posicionamento em um mapa ou desenho para determinar onde elas se encontram no ambiente de captura.
A câmera LadyBug 5 pode ser utilizada juntamente com um GPS (Global Positioning System), e com isso ter o posicionamento global de cada imagem. Isso é muito utilizado em ambientes externos, entretanto, em ambientes internos essa alternativa não se torna muito precisa, pois o sinal de GPS fica mais fraco pelas barreiras impostas pelas edificações, o qual atrapalha na precisão deste posicionamento. Dessa forma, o processo de posicionamento das imagens é feito manualmente com a ferramenta desenvolvida neste trabalho. $\mathrm{O}$ usuário terá que, por exemplo, utilizar uma planta baixa do ambiente interno ao qual a captura das imagens foi realizada, e esboçar um trajeto do percurso, formando o caminho percorrido no deslocamento de captura das imagens. As imagens panorâmicas são distribuídas igualmente pelo caminho percorrido, permitindo assim que se tenha uma referência de posicionamento para cada imagem. Para realizar essa distribuição, fazse necessário que o usuário informe a latitude e a longitude de dois pontos que devem ser referenciados na planta utilizada. Esses pontos são usados como referência no cálculo do posicionamento de todas as imagens do caminho. Se o usuário não tiver uma planta do local da filmagem, ele pode criar um esboço do local em algum ambiente de edição de imagem, para ter uma referência de posicionamento para as imagens. Os posicionamentos são gravados em um banco de dados, para serem recuperados pela aplicação Web que permite a visualização e navegação.

O banco de dados modelado para a ferramenta desenvolvida é apresentado na Figura 7. 


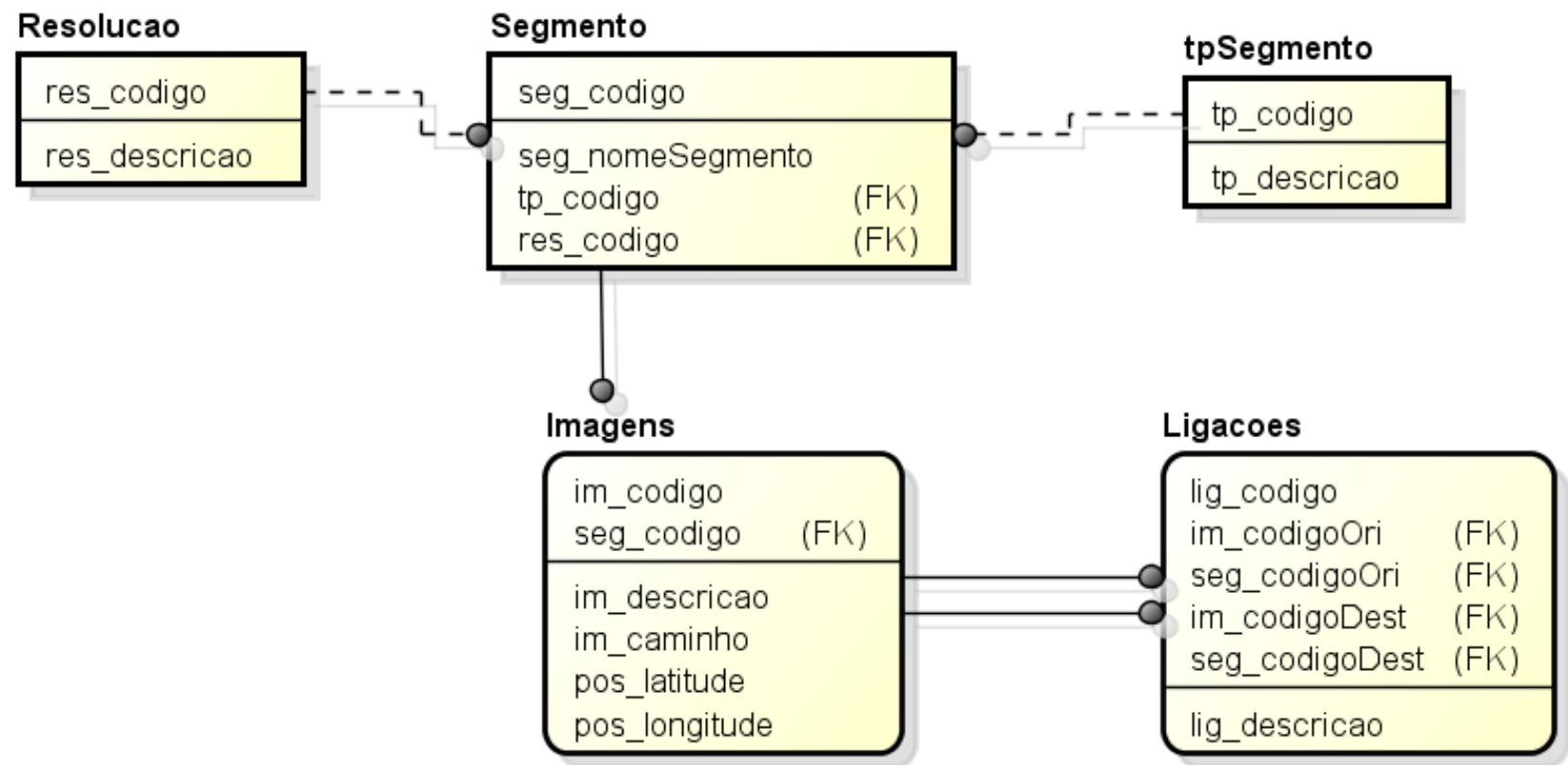

Figura 7. Modelo do banco de dados utilizado pela aplicação Web.

O banco de dados utilizado no projeto tem suporte para registrar informações como o nome dos segmentos, a resolução que as imagens desse segmento foram processadas, a categoria desse segmento (GPS ou planta), o caminho das imagens que constituem cada um dos segmentos e as ligações que são calculadas entre essas imagens. As ligações ocorrem quando uma imagem de um determinado segmento de origem é associada à outra imagem de outro segmento de destino. Isso permite a navegação seja mudada de um segmento ao outro quando houver um cruzamento.

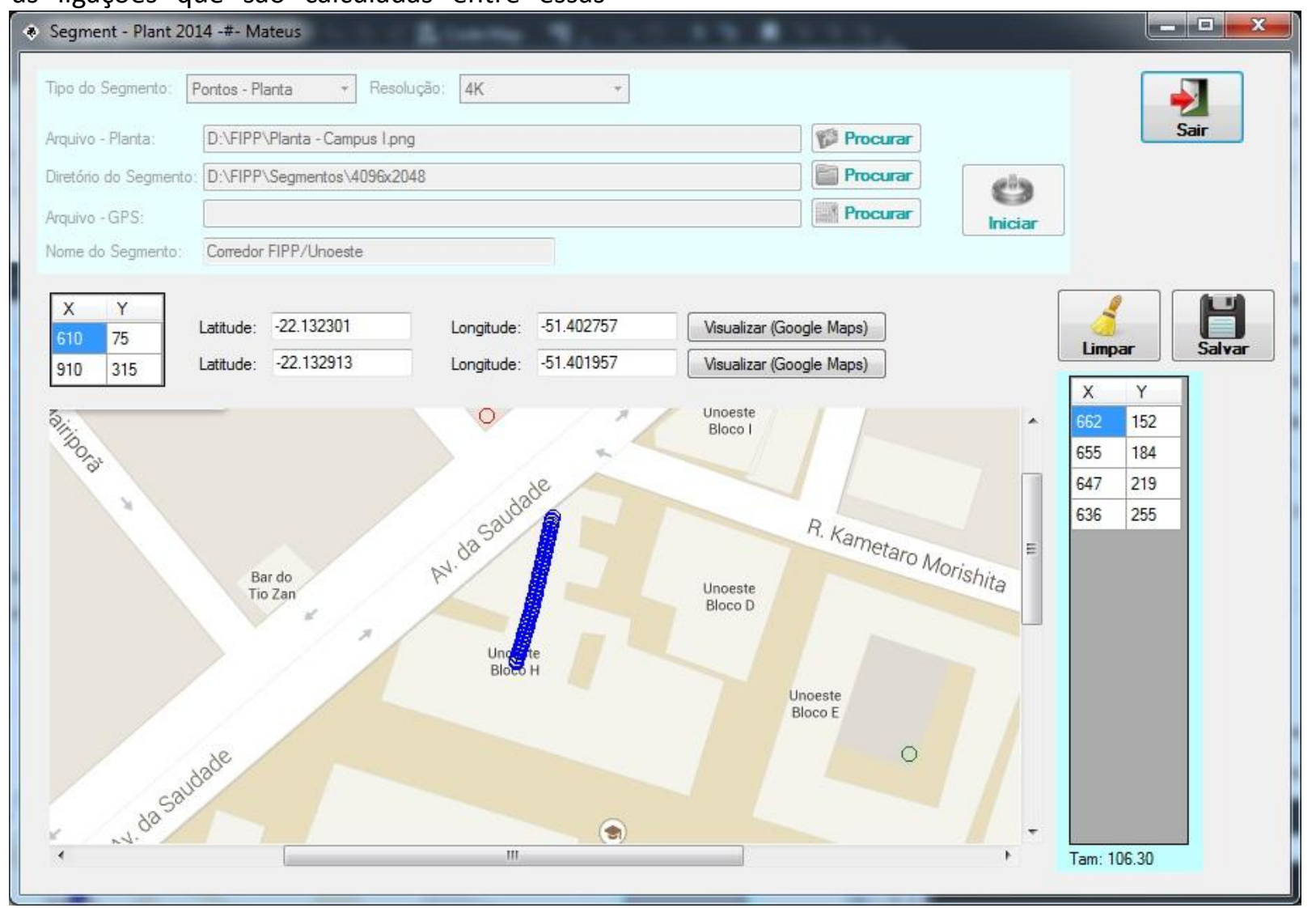

Figura 8. Ferramenta de catalogação das imagens panorâmicas para formar o caminho percorrido durante a filmagem. 
A ligação entre os segmentos é feita através da seguinte maneira. Inicialmente é calculada a distância das coordenadas das imagens de origem com as coordenadas das imagens de destino, a partir do posicionamento de latitude e longitude que são processadas na catalogação do segmento usando. A Equação 1 é utilizada para essa tarefa.

$$
\text { DistCord }=\sqrt[2]{(\text { LatOri }- \text { LatDest })^{2}+(\text { LongOri }- \text { LongDest })^{2}}
$$

Se esta distância (DistCord) for inferior a 0.00010 (equivalente à uma medida aproximada de 11 metros), estas coordenadas são candidatas ao processo de escolha da melhor distância entre diferentes segmentos para selecionar as imagens de origem e destino, em que será criada uma ligação entre os diferentes segmentos.

$\mathrm{Na}$ Figura 9 pode-se ver o diagrama de sequência do processo de catalogação das imagens que é feito utilizando a ferramenta apresentada na Figura 8.
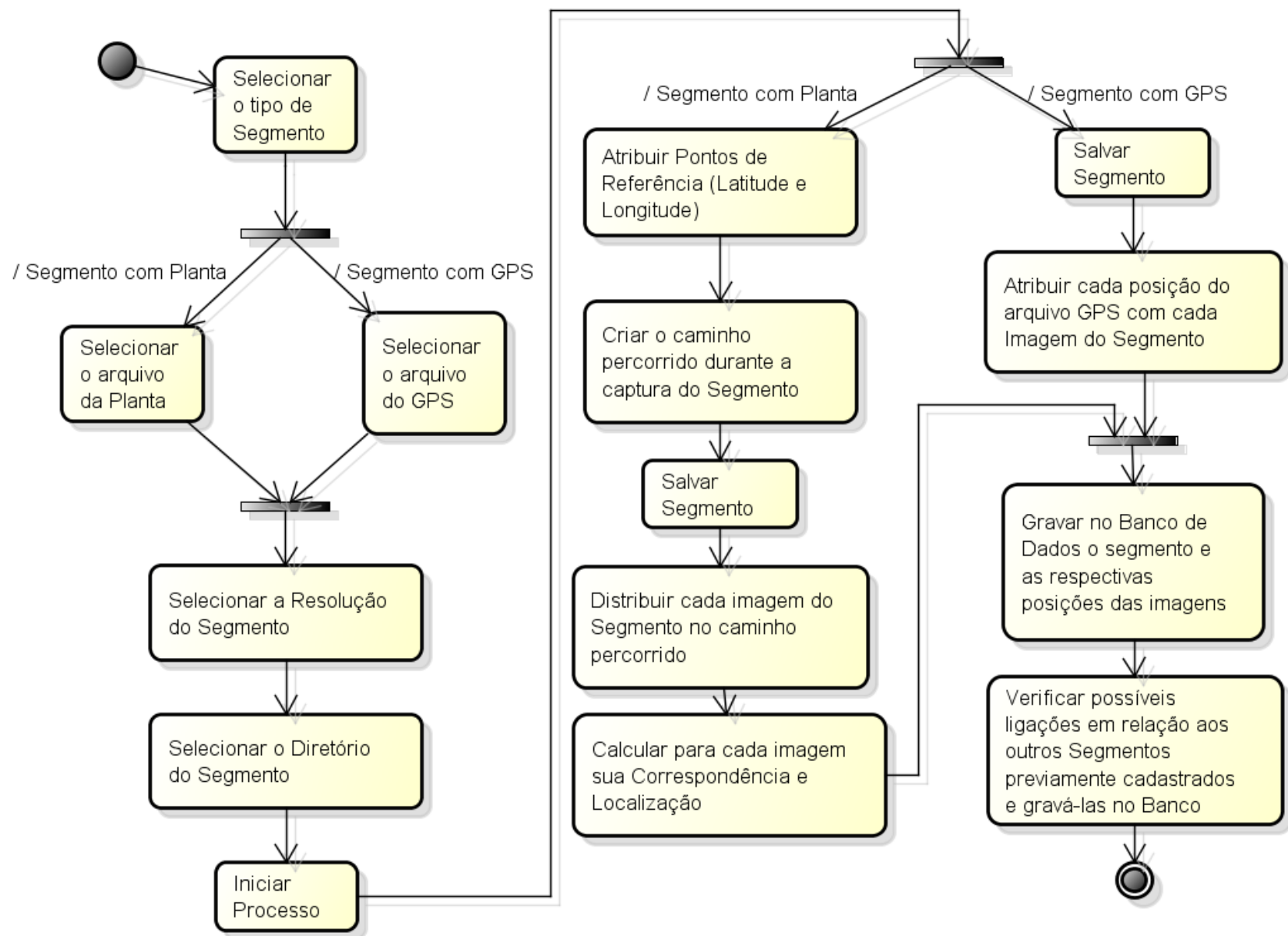

Figura 9. Diagrama de Sequência do processo de catalogação das imagens.

A navegação e visualização é realizada por uma aplicação Web desenvolvida utilizando HTML5, CSS3, JavaScript, e WebGL (Figura 10), que permite que o usuário mude o ângulo de visão durante a navegação nas imagens panorâmicas 360. Como se tem 15 imagens panorâmicas por segundo, de acordo com a taxa de captura da LadyBug 5, pode-se navegar na direção estipulada no ambiente interno, com as trocas dessas imagens de forma automática, como se tivesse visualizando um vídeo, ou de forma manual, configurando o ângulo de visão desejado. Quando em alguma parte do trajeto existir uma ligação com outro segmento, com um ou mais percursos, pode-se escolher a nova 
direção a ser tomada ou continuar a navegação frame a frame no trajeto original.

A troca de dados dos segmentos e suas ligações salvas no banco de dados entre o servidor e a aplicação Web foram feitas utilizando o formato JSON, pois de acordo com Fonseca e Simões (2007), a característica principal do JSON foi de ser projetado para ser simples, portável, textual e como um subconjunto do JavaScript. Por sua estrutura ser leve, diminui a transferência de dados entre o servidor e o navegador do usuário.

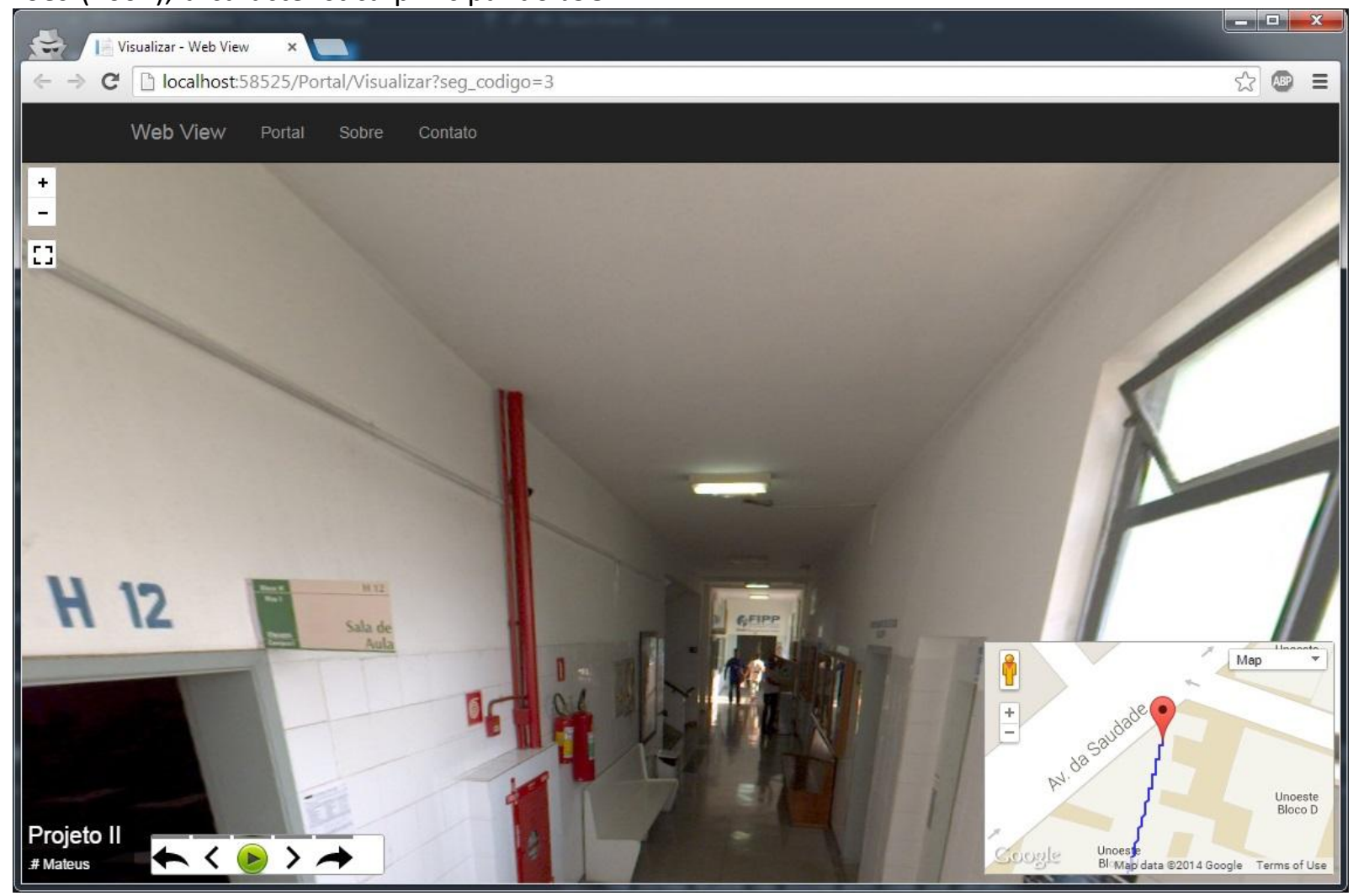

Figura 10. Aplicação Web para visualização das imagens.

A Figura 10, apresentada anteriormente, mostra uma imagem do ambiente interno de um dos corredores (Corredor FIPP 1) da FIPP (Faculdade de Informática de Presidente Prudente da Unoeste - Universidade do Oeste Paulista) que foram capturados. Na seção de experimentos e resultados deste trabalho, podem-se conferir as características de cada um dos segmentos capturados, como quantidade de imagens capturadas, localizações, etc. Na Figura 11 , pode-se visualizar uma imagem de um dos segmentos capturados, com nome atribuído Bloco $H-E$, esse segmento foi capturado no ambiente externo da Unoeste Campus I. Nessa imagem pode-se visualizar uma ligação com outro segmento Bloco H-A. Esta ligação é apresentada na imagem panorâmica por duas setas verdes. Outra seta que é apresentada em todas as ligações que aparecem durante a navegação, é uma seta branca com uma caixa em azul, permitindo que o usuário siga em frente no mesmo segmento de origem. Quando o usuário colocar o mouse em cima das setas que representam as ligações entre os diferentes segmentos, é apresentada uma descrição em relação ao nome do segmento que se tem a ligação, e quando o usurário selecionar uma destas setas, a navegação é efetuada para o outro segmento. Na Figura 12, pode-se conferir a mudança do segmento Bloco $\mathrm{H}-\mathrm{E}$ para o segmento Bloco $\mathrm{H}-\mathrm{A}$. 


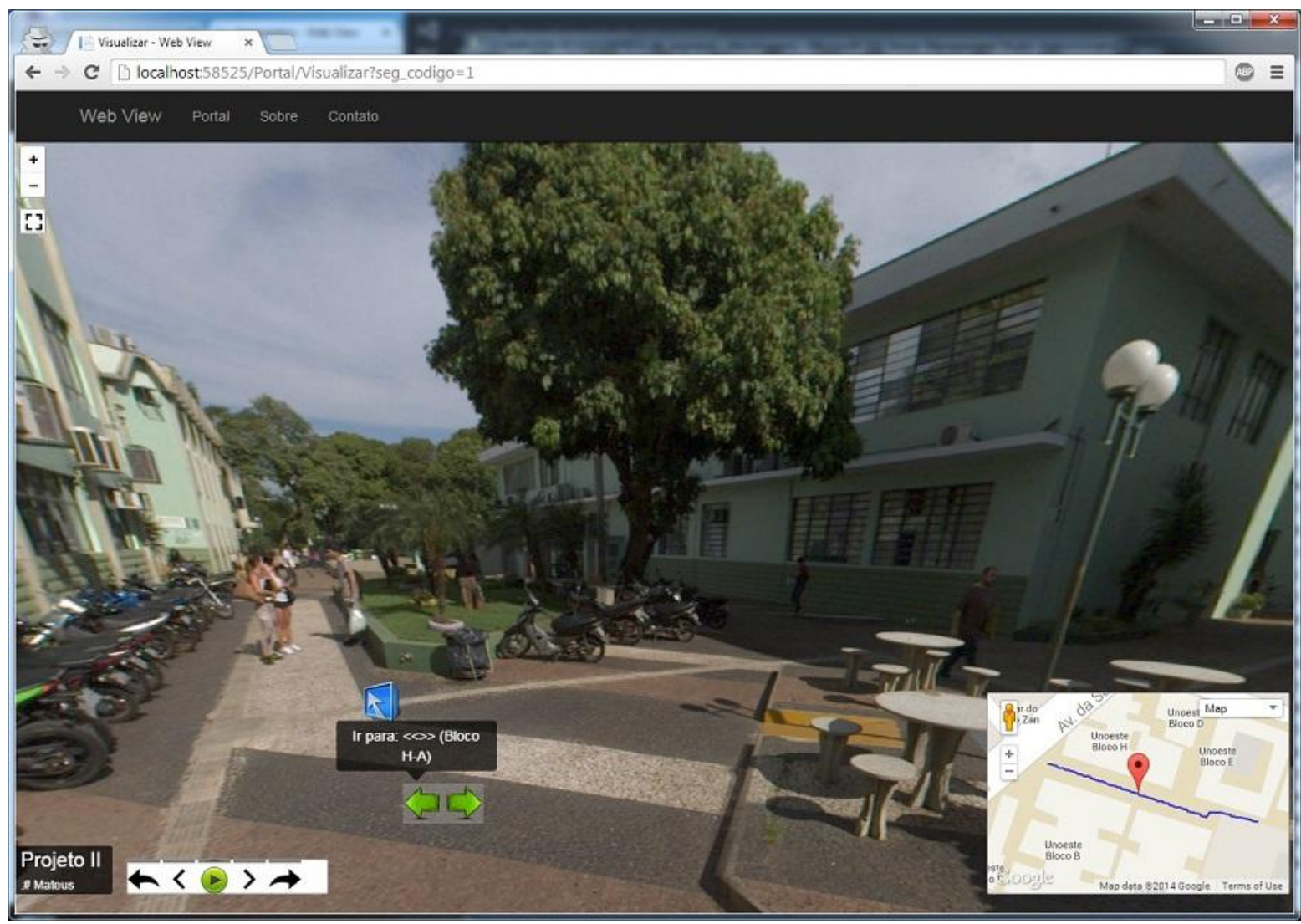

Figura 11. Segmento Bloco H-E do ambiente externo da Unoeste, com ligação para o segmento Bloco H-A.

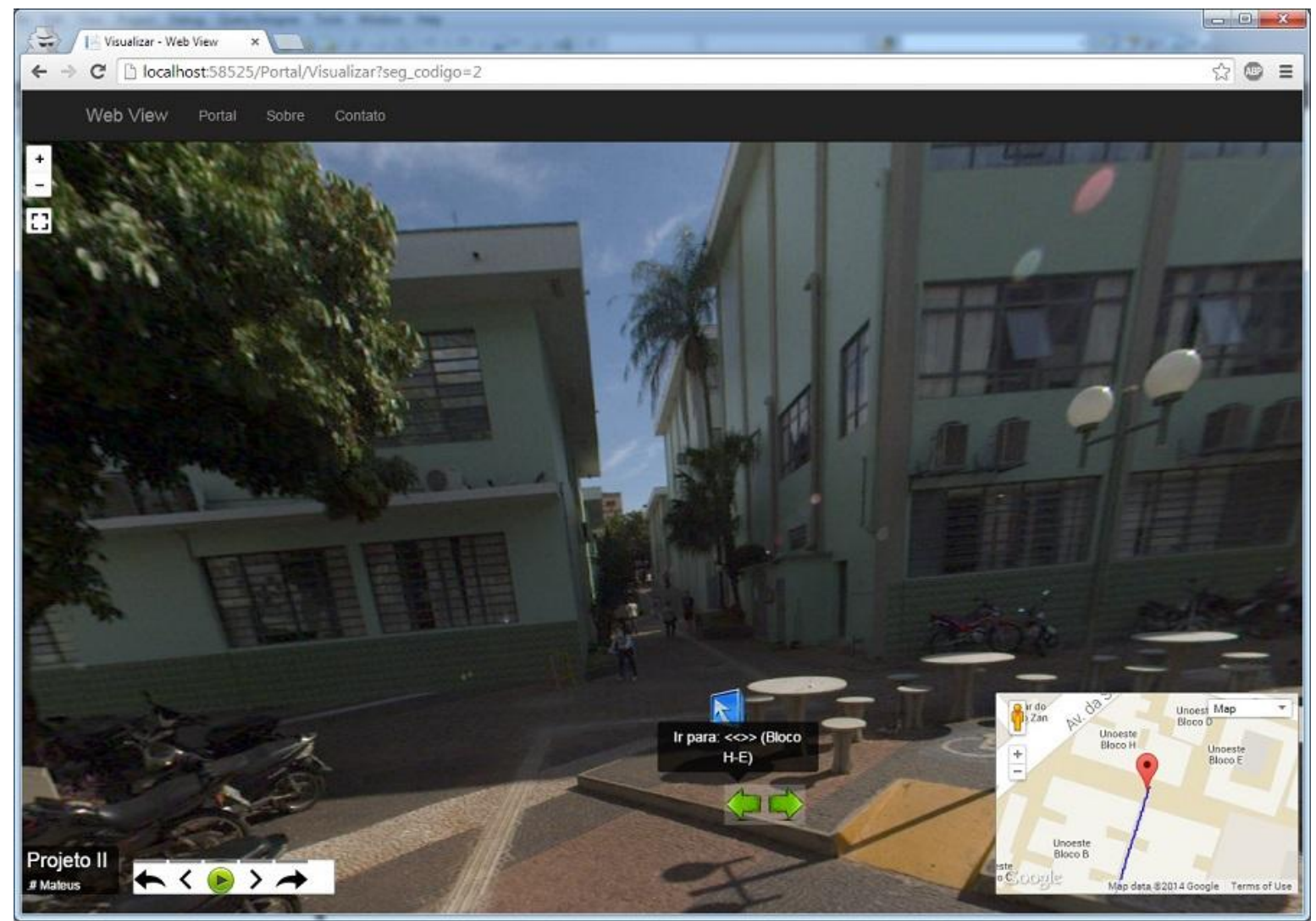

Figura 12. Segmento Bloco H-A do ambiente externo da Unoeste, com ligação para o segmento Bloco H-E. 


\section{EXPERIMENTOS E RESULTADOS}

No decorrer deste trabalho foram capturadas imagens tanto de ambientes internos quanto de ambientes externos, tendo o foco principal os ambientes internos, justamente pela dificuldade de se ter posicionamentos precisos dentro destes ambientes. Mas o processo de catalogação apresentado foi idealizado para os dois tipos de ambientes.

Foram realizados dois experimentos para demonstrar a eficiência do trabalho desenvolvido, experimento realizado em Ambiente Interno e outro realizado em Ambiente Externo.

\subsection{Experimento realizado em Ambiente Interno}

Para realizar este experimento, foi necessária a preparação do equipamento utilizado na captura dos segmentos apresentados na Tabela 1. Está incluso nesta preparação, a instalação e configuração da câmera LadyBug 5 no notebook que foi utilizado neste processo. Este notebook tem suporte a entrada USB 3.0, pela alta transferência de dados que a câmera necessita durante o processo de captura das imagens dos segmentos. Depois da captura dos segmentos, foi feita a extração e geração das imagens panorâmicas equirretangulares com o uso da ferramenta desenvolvida e mostrada na Figura 5. Após a geração das imagens panorâmicas equirretangulares, foi feita a catalogação dos segmentos usando a ferramenta desenvolvida e apresentada na Figura 8. Por fim, foi utilizada a aplicação Web desenvolvida para a navegação e visualização destes segmentos, permitindo assim, que o usuário interaja nestes ambientes que foram imageados.

Tabela 1. Descrição dos segmentos internos que foram capturados, com a quantidade e posicionamentos das imagens em cada segmento.

\begin{tabular}{c|c|c|c}
\hline Segmento Captura & $\begin{array}{c}\text { Quantidade de } \\
\text { Imagens }\end{array}$ & Posição Inicial & Posição Final \\
\hline Corredor FIPP 1 & 424 & $-22.132460,-51.402615$ & $-22.132640,-51.402675$ \\
\hline Corredor FIPP 2 & 481 & $-22.132665,-51.402529$ & $-22.132628,-51.402727$ \\
\hline
\end{tabular}

Na Tabela 1 tem-se a quantidade de imagens capturas, as posições iniciais e finais de cada um dos dois corredores capturados no ambiente interno do Bloco $\mathrm{H}$ da Unoeste no qual a FIPP se encontra instalada.
A Figura 13, mostra em um mapa com o esboço dos segmentos internos que foram capturados neste ambiente, ilustrando em cores os trajetos percorridos na captura destes segmentos apresentados na Tabela 1. 


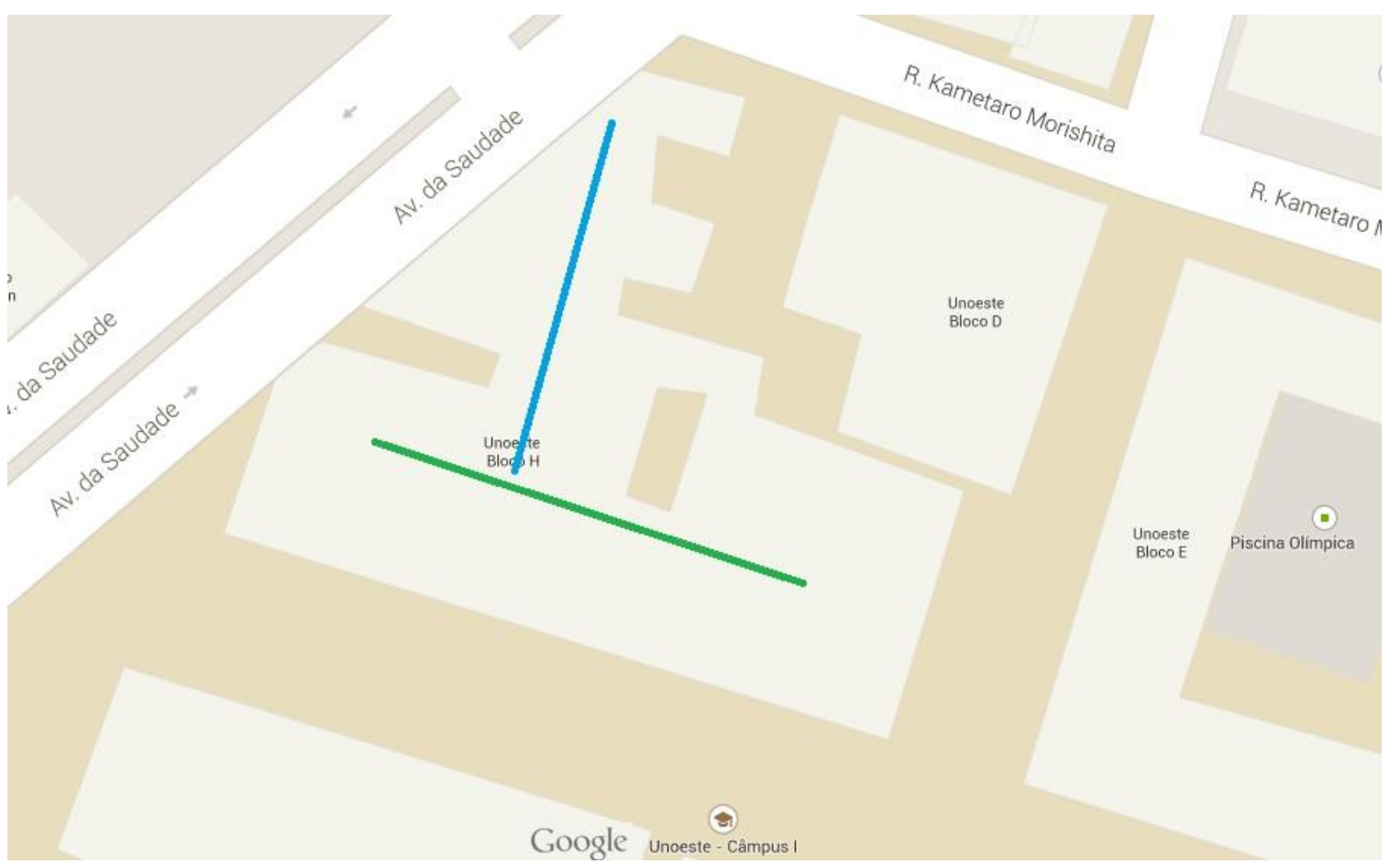

Figura 13. Esboço dos segmentos capturados em ambiente interno.

\subsection{Experimento realizado em Ambiente Externo}

$O$ experimento realizado em Ambiente Externo passou pelas mesmas etapas que foram apresentadas nos experimentos do ambiente interno, com a diferença do local de captura, que ao invés de ser nos corredores da FIPP, foram feitos nos calçadões da Unoeste no Campus I. A Tabela 2 mostra todos os calçadões dos blocos que foram capturada, com a câmera LadyBug, as imagens da Unoeste Campus I em seu ambiente externo.

Tabela 2. Descrição dos segmentos que foram capturados em ambiente externo, com a quantidade e posicionamentos das imagens em cada segmento.

\begin{tabular}{c|c|c|c}
\hline $\begin{array}{c}\text { Segmento } \\
\text { Captura }\end{array}$ & $\begin{array}{c}\text { Quantidade de } \\
\text { Imagens }\end{array}$ & Posição Inicial & Posição Final \\
\hline Bloco H-E & 1490 & $-22.132844,-51.403046$ & $-22.133104,-51.401967$ \\
\hline Bloco E-D & 906 & $-22.133026,-51.402331$ & $-22.132631,-51.402175$ \\
\hline Bloco H-A & 1381 & $-22.132999,-51.402556$ & $-22.133664,-51.402789$ \\
\hline Bloco A-B-C & 1799 & $-22.133761,-51.402475$ & $-22.133446,-51.403567$ \\
\hline Bloco C-H & 1212 & $-22.133503,-51.403299$ & $-22.132879,-51.403084$ \\
\hline
\end{tabular}

Os calçadões foram capturados de forma a permitir que no processo de criação dos percursos das imagens seja criada a ligação entre esses blocos, as quais são utilizadas na aplicação Web. A Figura 14 mostra em um mapa o esboço do trajeto de captura de cada um dos segmentos externos que foram capturados nas dependências da Universidade apresentados na Tabela 2. 


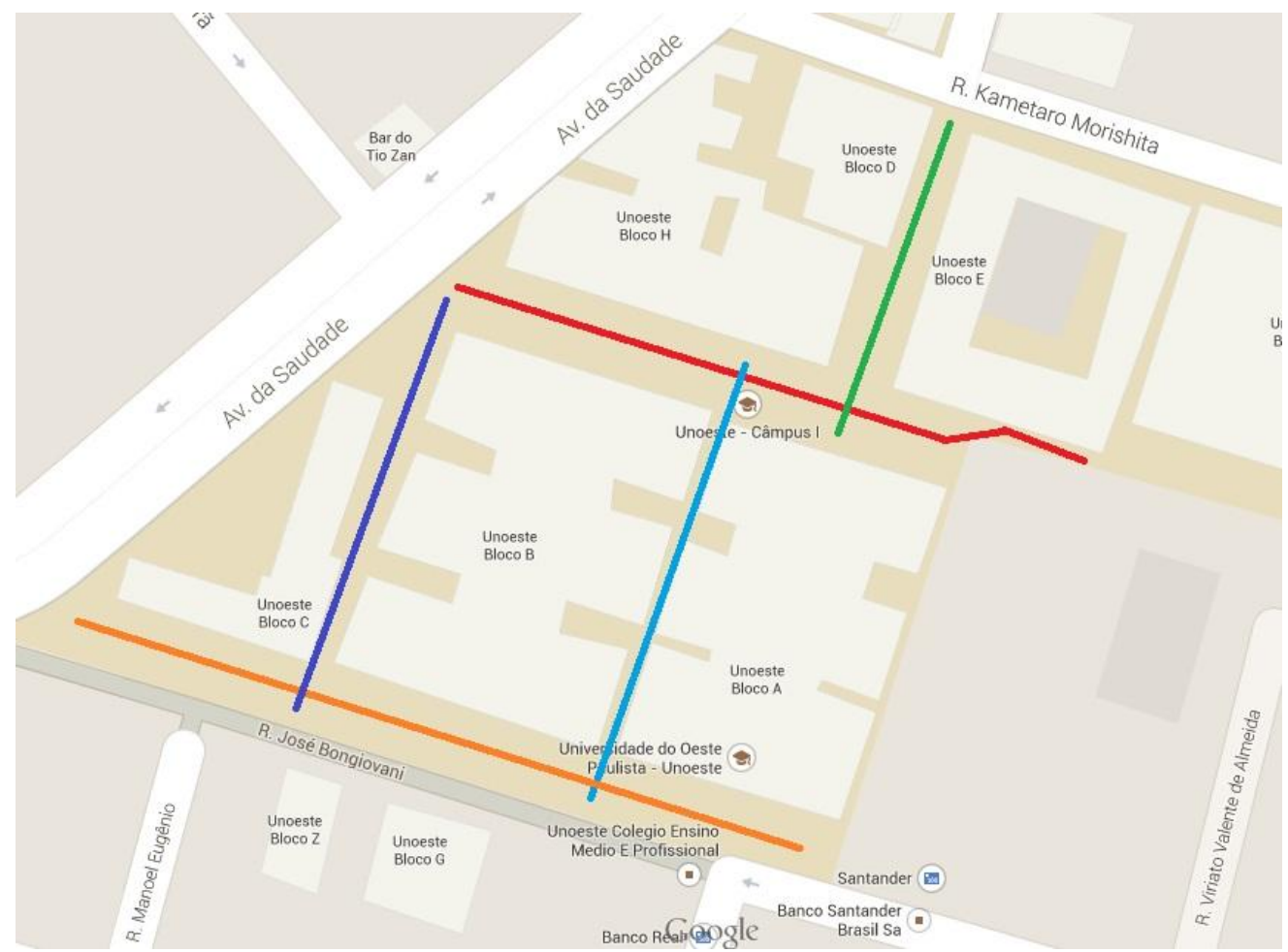

Figura 14. Esboço dos segmentos capturados em ambiente externo, calçadões do Campus I da Unoeste.

\section{CONSIDERAÇÕES FINAIS}

Este trabalho apresenta as etapas de captura de imagens usando uma câmera LadyBug 5 , extração e criação das imagens panorâmicas 360 equirretangular, uma ferramenta para criação dos segmentos dos percursos do ambiente de captura, e uma aplicação Web de navegação e interação. As ferramentas e a aplicação Web desenvolvidas podem ser utilizadas para fins de visualizações de ambientes internos de empresas, universidades entre outros. Essas imagens panorâmicas podem ser utilizadas para fins de divulgação, apresentação, cultural etc. Os resultados com os experimentos realizados foram de grande valia, pois a partir da realização das etapas apresentadas no projeto com os experimentos, notou-se que com a utilização dos recursos descritos neste trabalho, todo o processo foi simplificado, desde a extração das imagens até a visualização final destas imagens com a ferramenta Web desenvolvida, representando uma das contribuições deste trabalho. Por fim, os recursos necessários para a navegação e interação dos ambientes com o uso da aplicação Web, tem como finalidade facilitar a utilização desta aplicação, tendo em vista que pode ser executada em qualquer Sistema Operacional que tenham um navegador Web com suporte a HTML5, CSS3, JavaScript, and WebGL.

\section{REFERÊNCIAS}

ÁLVARES, C. M. Vídeos interativos e imersivos no sight surfers. 2012. 75 f. Dissertação (Mestrado em Engenharia Informática) - Universidade de Lisboa, Faculdade de Ciências, Lisboa.

ARTH, C. et al. Real-time self-localization from panoramic images on mobile devices. In: IEEE INTERNATIONAL SYMPOSIUM ON MIXED AND AUGMENTED REALITY 2011. Proceedings... Graz University of Technology, Austria, p. 37-46, 2011. http://dx.doi.org/10.1109/ISMAR.2011.6092368

FONSECA, R.; SIMÕES, A. Alternativas ao XML: YAML E JSON. In: ACTAS DA CONFERÊNCIA NACIONAL, 5. Anais... Lisboa, 2007. p. 33-46.

HU, O. R. T. et al. Vídeo panorâmico 360 para sistemas de telepresença. In: OCTAVA CONFERÊNCIA IBEROAMERICANA EN SISTEMAS, CIBERNÉTICA E INFORMÁTICA: CISCI 2009. Anais... Flórida, 2009.

LOWE, D. G. Distinctive image features from scale-invariant keypoints. International Journal of Computer Vision, v. 60, n. 2, p. 91-110, 2004. http://dx.doi.org/10.1023/B:VISI.0000029664.99 $\underline{615.94}$

MORATO, L. Quicktime virtual reality e estereofotografia: utilizando técnicas fotográficas 
imersivas para a divulgação da Espeleologia no Brasil. In: CONGRESSO BRASILEIRO DE ESPELEOLOGIA, 30. Anais... Montes Claros MG, 09-12 de julho de 2009.

RIBEIRO, N. M. S. Fotografia panorâmica aplicada a visitas virtuais em contexto escolar. 2012. 122 f. Dissertação (Mestrado em Expressão Gráfica e Audiovisual) - Universidade Aberta, Lisboa.

SILVA, F. A. et al. StitchingPHm - a new algorithm for panoramic images. Pattern Recognition and Image Analysis, v. 24, n. 1, p. 41-56, 2014. http://dx.doi.org/10.1134/S1054661814010167

SINGH, G.; KOSECKÁ, J. Acquiring semantics induced topology in urban environments. In: IEEE INTERNATIONAL CONFERENCE ON ROBOTICS AND AUTOMATION. Proceedings... RiverCentre, Saint Paul, Minnesota, USA, p. 3509-3514, 2012. http://dx.doi.org/10.1109/icra.2012.6225282

SOARES, E. C. M. Ciberespaço, vigilância e privacidade: o caso Google Street View. Ciberlegenda, n. 25, 2011. 